\title{
ERRATUM
}

\section{Immunotherapeutic Approach to Cancer with Cutaneous DNA Vaccination}

\author{
Wilbur B. Browne, William G. Hawkins, and Jonathan J. Lewis
}

J. H. Mydlo (ed.) Methods in Molecular Medicine, vol. 53: Renal Cancer: Methods and Protocols, DOI 10.1385/978-1-59259-144-2, pp. 313-321, (C) Springer Science+Business Media, LLC 2001

DOI 10.1385/978-1-59259-144-2_26

The publisher regrets that in the online version of this book including PubMed, the name of the author Wilbur B. Bowne was listed incorrectly as Wilbur B. Browne in the Table of Contents and in Chapter 20. 